\title{
Spiritual Histories and Latter-day Saints: A Mixed-Method Preliminary Validation Study
}

\author{
David R. Hodge \\ Gordon E. Limb
}

\begin{abstract}
Spirituality plays a primary role in health and wellness for many Latter-day Saints (LDS). Despite being one of the largest religious cultures in the nation, few, if any, spiritual assessment tools have been validated with this population. This mixed-method study modifies an existing spiritual assessment approach-spiritual histories-that may be congruent with LDS culture. Using a national sample of experts in LDS culture $(N=$ 100), this study identifies: 1) the degree of cultural consistency, strengths, and limitations of the approach at a conceptual level, and 2) a culturally valid question protocol to operationalize the concept for use with LDS clients. The results suggest that spiritual histories represent a highly appropriate assessment method for LDS clients. The paper concludes by providing suggestions to administer an assessment in a culturally competent manner in clinical settings.
\end{abstract}

Keywords: Spirituality, assessment, spiritual history, Latter-day Saints, Mormons

Mormons, or Latter-day Saints (LDS) as they often prefer to be called, now represent the fourth largest religious denomination in the United States (Linder, 2011; Melton, 2009). LDS can be found in every state in the union, although they are concentrated in the mountain west states and Utah in particular (Pew Research Center, 2012). From their origin in the US in the 1820s, the Church of Jesus Christ of Latter-day Saints has grown to the point that more members now reside outside the US than inside (Haynes, 2001). This growth is fueled by comparatively high birth rates and conversions, and is expected to continue. The projected growth of the Church suggests that therapists will increasingly encounter LDS clients in the future regardless of their state of residency (Ulrich, Richards, \& Bergin, 2000).

LDS comprise a distinct cultural population (Cnaan, Evans, \& Curtis, 2012; Marks, 2004). As Haynes (2001) notes, LDS' spiritual identity serves to frame life experience in much the same way that race or ethnicity often do for other people. This spiritual identity provides a worldview that functions to shape, order, and interpret life experiences. Put differently, for LDS spirituality is not so much a Sunday morning event as it is a distinct way of life, a cultural grid through which reality is experienced (Anderson, 2008). This is not to say that LDS are the only faith group for which this is true. Muslims (Hodge, 2002), Native Americans (Hodge, Limb, \& Cross, 2009), Hindus (Hodge, 2004), and many other spiritual groups (Van Hook, Hugen, \& Aguilar, 2001) also view reality through a spiritual lens. Rather, as is the case for many people of faith, LDS religious culture provides a grid through which events are understood and interpreted.

David R. Hodge, Ph.D., is an Associate Professor in the School of Social Work at Arizona State University in Phoenix and Senior Nonresident Fellow at the University of Pennsylvania’s Program for Research on Religion and Urban Civil Society. Gordon E. Limb, Ph.D., is an Associate Professor in the School of Social Work at Brigham Young University in Provo, UT

Copyright (c) 2013 Advances in Social Work Vol. 14 No. 2 (Fall 2013), 379-394 
For example, Loser, Klein, Hill, and Dollahite (2008) examined the way in which religion affected day-to-day activities among a sample of LDS families. Respondents typically reported that religion was strongly integrated into their lives. Analysis indicated that religion influenced every ecological system examined: individual, familial, structural, and social.

In turn, LDS cultural values can play an important role in service provision. Thomas, Cunningham, and Donnell (2011) examined the pattern of symptom reduction among LDS and non-LDS clients. The results revealed differential efficacy between the two groups, a finding that underscores the importance of considering LDS values when providing services to this population.

Indeed, it is essentially impossible to work effectively with LDS clients without understanding the role that spirituality and religion plays in clients' lived realities (Haynes, 2001). As the NASW Standards for Cultural Competence in Social Work Practice (2001) imply, effective service provision is contingent upon understanding the role of clients' spiritual beliefs and values. A spiritual assessment that explores the role of spirituality and religion in clients' lives is indispensable if practitioners hope to work effectively with LDS clients (Canda \& Furman, 2010; Haynes, 2001; Loser et al., 2008; Marks, 2004).

In spite of its importance, little research has been conducted on spiritual assessment from a LDS perspective. A search of Social Services Abstracts (5/18/2012) using the keywords "Mormon" or "Latter-day Saint" or "LDS" yielded 45 articles, none of which focused on spiritual assessment. This is consistent with research indicating most social workers report receiving little, if any, content on spirituality and religion during their graduate educations (Canda \& Furman, 2010; Sheridan, 2009).

The lack of culturally relevant spiritual assessment tools is disconcerting. As noted above, LDS have unique cultural values that can (Marks, 2004), if not taken into account, lead to differential treatment outcomes (Thomas et al., 2011). In addition, LDS have a history of being oppressed by dominant groups (Ulrich et al., 2000). Misconceptions and biases among the general population continue to exist as seen in public polling data indicating that the Mormon faith is one of the least liked and/or understood religions in the nation (Chen, 2011).

Latter-day Saints also report that extensive misinformation exists about their beliefs and values. Approximately 62\% of LDS report that Americans are misinformed about Mormonism (Pew Research Center, 2012). When asked to describe the most important problems facing LDS, 56\% report misperceptions about their beliefs, discrimination, lack of acceptance in American society, and similar themes (Pew Research Center, 2012). In light of these data, it is unsurprising that some commentators report that LDS clients may be hesitant to trust practitioners due to concerns about lack of cultural competency (Ulrich et al., 2000).

The need for culturally relevant assessment approaches is accentuated by the fact that spiritual assessments are now mandated in many settings frequented by LDS. The Joint Commission - the largest health care accrediting organization in the United States- 
requires the administration of spiritual assessments in, for example, hospitals, long term care facilities, and behavioral health care organizations providing addiction services (Hodge, 2006).

Since practitioners are required to conduct spiritual assessments with LDS clients, it is imperative that assessment tools are developed that are valid, relevant, and consistent with LDS culture, especially given the lack of training on spirituality and religion reported by most practitioners (Canda \& Furman, 2010; Sheridan, 2009). To provide effective, ethical services to LDS clients, it is necessary to explore clients' spirituality with tools that have been shown to be culturally relevant by members of this population. Accordingly, this study modifies an existing spiritual assessment tool for use with LDS clients. In the following section, the tool is overviewed and research questions are delineated.

\section{Spiritual Histories}

One assessment approach that may be congruent with LDS culture is the concept of a spiritual history. Spiritual histories are among the more widely used approaches to assessment (Canda \& Furman, 2010; Furness \& Gilligan, 2010; Pargament, 2007). With this approach, a particular set of questions is used to elicit a client's spiritual story in a manner analogous to eliciting a family history. For LDS clients, spiritual histories are similar in nature to the idea of family histories - an important LDS church doctrine (Haynes, 2001).

Table 1 features one approach to operationalizing a spiritual history. This approach consists of two question sets, which are used to help practitioners explore clients' spiritual stories (Hodge, 2001). The narrative question set provides practitioners with some possible questions to help clients relate their spiritual stories, typically moving from childhood to the present.

The anthropological question set is designed to elicit spiritual information as clients relate their stories. Based upon the work of Nee (1968), this anthropological framework posits the existence of three dimensions of personality — affect, behavior, and cognition and three dimensions of spirit-communion, conscience, and intuition. Communion refers to the ability to bond or relate to God (or the Transcendent). Conscience relates to one's ability to sense right and wrong. Intuition refers to the ability to know-to obtain insights that bypass normal cognitive channels. In each of these six intertwined dimensions, questions are provided to explore clients' spiritual strengths and values.

As clients relate their spiritual narratives (prompted, if needed, by items from the narrative question set), they often touch upon some of the six anthropological dimensions (Hodge, 2001). If the area warrants further clinical exploration, practitioners can use items from the anthropological question set to explore clients' spiritual reality in greater depth. In short, the narrative questions help clients tell their stories while the anthropological questions assist practitioners to draw out clinically salient spiritual information as the stories unfold. 
Table 1. Spiritual History Question Sets for General Population

\section{Narrative Question Set}

Describe the spiritual/religious tradition in which you grew up. How did your family express its spiritual beliefs? How important was spirituality to your family? Extended family?

What sort of personal experiences (rituals, ceremonies, or practices) stand out to you during your years at home? What made these experiences noteworthy? How have they informed your later life?

How have you changed or matured from those experiences? How would you describe your current spiritual or religious orientation? Is spirituality currently a personal strength? If so, how?

2. Anthropological Question Set

- Personality

Affect: What aspects of your spiritual or religious life give you pleasure? What role does your spirituality play in handling life's sorrows? Enhancing life's joys? Coping with life's pain? How does your religion or spirituality give you hope for the future? What do you wish to accomplish in the future?

Behavior: Are there particular spiritual beliefs, ceremonies, or practices that help you deal with life's obstacles? What is your level of involvement in spiritual communities, such as church, spiritual groups, etc.? How are they supportive? Are there spiritually encouraging individuals that you maintain contact with?

Cognition: What are your current spiritual/religious beliefs? What are they based upon? What beliefs do you find particularly meaningful? What does your faith say about personal trials? How does this belief help you overcome obstacles? How do your beliefs affect your health practices?

\section{- $\quad$ Spirit}

Communion: Describe your relationship with God (or Father in Heaven, etc.). What has been your experience of God? How does God communicate with you? How have these experiences encouraged you? Have there been times of deep spiritual intimacy? How does your relationship help you face life challenges? How would God describe you?

Conscience: How do you determine right and wrong? What are your key values? How does your spirituality help you deal with wrongdoings or guilt? What role does forgiveness play in your life?

Intuition: To what extent do you experience intuitive hunches (flashes of creative insight, premonitions, spiritual insights)? Have these insights been a strength in your life? If so, how?

Adapted from Hodge (2003).

As implied above, the purpose of this present study was to modify this assessment tool for use with LDS. Toward this end, this mixed-method study sought to answer two broad questions regarding the tool and its operationalization. First, as a general concept, how consistent was this particular assessment approach with LDS culture and what were its strengths and limitations for working with LDS clients? Second, in terms of operationalizing the concept, how consistent were the questions featured in Table 1 with 
LDS culture and how might they be improved or changed to be more valid, relevant and consistent with LDS culture?

\section{Method}

\section{Participants}

To answer these two questions, the study surveyed a sample of practitioners with extensive practice experience with LDS clients. To identify "experts" in LDS culture, a hybrid purposive/snowball sampling strategy was used (Babbie, 2010). The second author served as the Director of the School of Social Work at Brigham Young University, an LDS university, at the time the study was conducted. This author, who has numerous professional contacts in the LDS community through his professional affiliation, contacted a number of potential participants in different geographic regions throughout the United States. The purpose of the present study was explained to these individuals, and they were asked to identify other practitioners with extensive knowledge of LDS culture. All correspondence was conducted via email and was personalized in keeping with research suggesting that this practice enhances response rates (Heerwegh, Vanhove, Matthijs, \& Loosveldt, 2005).

Using this approach, 125 social work practitioners with at least five years of practice experience with LDS clients were identified. Of these, 100 participated in the study, resulting in an $80 \%$ response rate. Participant solicitation continued until the number of practitioners from a given geographical area was roughly proportional to the national LDS population residing within the same area, according to data obtained from the Church's official website (www.lds.org).

Table 2 lists the demographic characteristics of the sample. A majority of respondents resided in the western United States. Most of the respondents were LDS and white, with a slight preponderance being male. The average respondent was approximately 44 years-old and reported working in the profession for just over 13 years since obtaining their social work degree, suggesting that the participants were well situated to complete the survey.

\section{Apparatus}

To develop the mixed-method survey, the authors first modified the questions featured in the original spiritual assessment instrument to eliminate obvious inconsistencies with LDS culture. The first author has expertise in different spiritual traditions and, as alluded to above, the second author works in an LDS cultural context. Only very clear inconsistencies were revised. For example, the original question set used the term "the Ultimate" to refer to an entity that holds ultimate sacred or transcendent meaning within a particular spiritual narrative (i.e., "Describe your relationship to the Ultimate.”). Both authors agreed that this terminology is foreign to LDS culture, where individuals talk about "God' rather than "the Ultimate." In addition, rather than having a relationship to God, people have a relationship with God in the LDS narrative. Thus, the 
question "Describe your relationship to the Ultimate" was changed to "Describe your relationship with God.”

Table 2. Participant Characteristics $(N=100)$

\begin{tabular}{lrrr}
\hline Characteristic & $\%$ & $M$ & $S D$ \\
\hline Region & 59 & & \\
$\quad$ West & 10 & & \\
$\quad$ Southwest & 8 & & \\
$\quad$ Northwest & 9 & & \\
$\quad$ Midwest & 14 & & \\
$\quad$ East & & & \\
Religion & 98 & & \\
$\quad$ LDS & 2 & & \\
$\quad$ Other & 89 & & \\
Race & 11 & & \\
$\quad$ White & & & \\
$\quad$ Other & 55 & & \\
Gender & 45 & & \\
$\quad$ Male & & & \\
$\quad$ Female & 100 & & \\
Social Work Degree & & & \\
$\quad$ Yes & & & \\
Yrs. in Profession & & & \\
Age & &
\end{tabular}

This initial survey was then pilot tested with six LDS faculty at Brigham Young University. These individuals were asked to assess the survey's content and design for clarity and face validity. Minor changes were made based on the provided feedback. For example, individuals noted that a widely used synonym for God in LDS culture is "Father in Heaven" or "heavenly Father." Thus, the survey was revised to include the phrase "Father in Heaven" in brackets after God at one point in the instrument to clarify to potential respondents that practitioners operationalizing the assessment had the freedom to use such terms [i.e., "Describe your relationship with God (or Father in Heaven, etc.)"].

In keeping with the two research questions, the final survey included 1) a general conceptual overview of the spiritual history instrument discussed above and 2) the questions designed to operationalize the concept featured in Table 1. After being presented with an overview of the general concept, participants were asked to assess the consistency of the concept with LDS culture on an 11-point scale in which 0 corresponded to the complete absence of consistency with LDS culture, while 10 corresponded to complete consistency with LDS culture (Hodge \& Gillespie, 2007). 
Two open-ended questions were used to identify the strengths and limitations of the concept in work with LDS clients. The question concerning strengths asked, "In terms of working with LDS clients, what are the strengths of spiritual histories?" This was followed by a similar item using the term "limitations" instead of "strengths."

As implied above, the survey also included the question sets listed in Table 1 for the narrative framework: affect, behavior, cognition, communion, conscience, and intuition. Each of the seven question sets was followed by two questions. A quantitative item was used to assess the overall consistency of the question set with LDS culture using the 11point scale discussed above. This question was followed by a qualitative item designed to identify ways in which the questions could be modified to be more congruent with LDS culture. More specifically, the item asked, "How could these questions be improved to be more valid, relevant, and consistent with LDS clients?”

\section{Procedures}

The survey instrument was placed online and the URL link was emailed to practitioners who agreed to participate in the study. Individuals were concurrently informed that a paper copy of the survey was available, although no one requested this option. This result is consistent with research indicating that educated professionals prefer web surveys over mail surveys (Barrios, Villarroya, Borrego, \& Olle, 2011). Although studies suggest the data obtained is generally similar for both formats, some research indicates that web surveys may yield somewhat higher quality data in answer to qualitative questions (Barrios et al., 2011; Shin, Johnson, \& Rao, 2012). Participants received a $\$ 50$ honorarium for their time spent in completing the survey.

\section{Data analysis}

After cleaning the quantitative data, tests of associations were conducted between the dependant variables and the demographic variables reported in Table 2 when statistical assumptions were met. For the qualitative data, a constant comparative methodology was used (Corbin \& Strauss, 2008). In this approach, data are examined for similarities, patterns, and common themes (Dye, Schatz, Rosenberg, \& Coleman, 2000). In a recursive process, the emerging themes are continually compared to similar phenomena across survey instruments. Primary themes were identified, organized, and labeled. Direct quotes are used to illustrate the themes. As a final supplementary step, the data were synthesized to develop an alternative question protocol to operationalize spiritual histories with LDS clients in a more culturally valid manner.

\section{Results}

The results are presented in two subsections that reflect the study's two research questions. The first subsection reports the findings on the cultural consistency, strengths, and limitations of spiritual histories at a conceptual level. The second subsection reports on the operationalization of the concept, specifically the cultural consistency of the various question sets and how they might be improved. This sub-section concludes with an alternative spiritual history protocol, based upon respondents' suggestions. 


\section{General Concept: Consistency, Strengths, and Limitations}

As a group, respondents reported the concept of conducting a spiritual history was generally consistent with LDS culture, as indicated by the mean of score of 8.06 on the 0 to 10 scale (see Table 3 ). The mode was 10, indicating a plurality of respondents believed the concept was completely consistent with LDS culture. These perceptions were stable across the demographic characteristics. Region of residence, gender, years of professional experience, and age were all unrelated to perceptions of cultural consistency.

Table 3. Perceptions of Consistency with LDS Culture $(N=100)$

\begin{tabular}{lcc}
\hline Area & $M$ & $S D$ \\
\hline Spiritual histories as a general concept & 8.06 & 1.68 \\
Narrative Question Set & 8.48 & 1.45 \\
Anthropological Question Set & & \\
$\quad$ Affect & 8.70 & 1.47 \\
Behavior & 8.39 & 1.61 \\
Cognition & 8.94 & 1.30 \\
Communion & 8.71 & 1.53 \\
Conscience & 9.03 & 1.15 \\
Intuition & 8.15 & 1.62 \\
\hline
\end{tabular}

The qualitative question regarding strengths helped illuminate the relatively high cultural consistency score. Analysis indicated that the most prominent asset of the concept is its narrative format. As various respondents stated, "It allows clients to tell their story and be validated in the story telling," and "Allows clients to tell their stories in their own words." Others noted that sharing one's spiritual story or testimony is a common practice in LDS culture and, correspondingly, the approach should resonate with LDS clients. Additional themes included the approach's ability to provide: insights into important beliefs and practices; information about coping strategies and resources, and points of spiritual tension; opportunities to build rapport with clients; and the therapeutic benefit of being able to relate one's story in a supportive context.

The question regarding limitations served to qualify these strengths. The three most widely mentioned concerns were intertwined and centered upon: a) the sensitive nature of LDS spirituality, b) practitioners' lack of cultural competency, and c) the use of terminology that is inconsistent with LDS culture. As respondents noted, many dimensions of LDS spirituality are highly sacred and/or personal in nature. Consequently, clients may be hesitant to share their spirituality with non-LDS practitioners for fear of being misunderstood, labeled irrational, or otherwise disparaged. Other, less prominent limitations cited include: the unreliable nature of memories, the time required to conduct a complete assessment, the potential to elicit too much detail, and the approach's relatively poor fit with clients who are less verbally or spiritually oriented. 


\section{Operationalization: Consistency and Improvements}

As can be seen in Table 3, the means for the narrative framework and the six dimensions of the anthropological framework indicated a relatively high level of consistency with LDS culture. As was the case above, perceptions were stable across the demographic variables. The mode was 10 for each question, with two exceptions (9 for both the narrative framework and the intuition dimension). Reflecting the high mode values, many respondents endorsed the present operationalization (e.g., "These are great questions"), which was a theme that emerged for all the subsequent questions. Accordingly, only unique themes are reported below to conserve space.

Narrative Framework-Analysis revealed three themes: eliminate language that is inconsistent with LDS culture, use less intellectual terminology, and less frequently, talk about religion rather than spirituality. Regarding the first theme, many respondents noted terms such as "rituals, ceremonies, or practices" are not common in LDS culture and can even have negative connotations with some clients. Accordingly, respondents recommended terms that have specific meaning within the LDS tradition (e.g., "family home evenings," "baptisms," "blessings," "missions,"). Respondents also recommended replacing more intellectually oriented language (e.g., "informed," “orientation,” \& "matured") with direct, clear terminology that reflects typical LDS practice. For instance, it was noted that LDS frequently talk about levels of activity in Church functions. Others suggested that talking about religion, rather than spirituality, would be more commonplace in LDS culture.

Affect-Two prominent themes emerged from the analysis. First was the use of "pleasure." Many respondents noted that the term "pleasure" is inconsistent with LDS values. As one person observed, "it often has negative connotations." In its place, respondents recommended using terms such as "joy," "meaning," "purpose," "endure," "happiness," and "comfort." Another theme concerned the need to create space for negative emotions. For example, one respondent noted that some clients may wrestle with guilt if they do not successfully live up to the teachings of the Church.

Behavior-Analysis yielded three themes. Respondents noted that many of the questions were too vague and lacked resonance with LDS culture. For example, one respondent noted that "spiritual groups is not a common LDS term." In a closely related theme, respondents recommended using familiar LDS terms to set clients at ease. For example, instead of "ceremonies," terms such "ordinances," "temple worship," and "prayer" were suggested; instead of "spiritual communities," respondents suggested using "ward," "branches," and "stakes"; instead of "spiritually encouraging individuals," using "religious leaders" or more specifically "bishop," "stake president," or "relief society president." A less frequently mentioned theme was the sensitive nature of some LDS practices. As one respondent noted, some practices are sacred and should not be discussed with non-LDS members.

Cognition-Analysis produced two themes. First, respondents noted that the question about health practices intersected with a specific LDS teaching called the "Word of Wisdom" (i.e., abstinence from tobacco, coffee, tea, and harmful drugs). Some recommended eliminating this question or asking a more direct question if the 
practitioner was interested in clients' health (e.g., "How do your beliefs affect your ... physical health?"). Another theme that emerged was the broad nature of the first question-What are your current spiritual/religious beliefs? To keep the session focused in light of the expansive nature of LDS teaching, respondents recommended asking a more focused question.

Communion-Analysis yielded four themes. Respondents noted the personal nature of this content area and raised questions about the willingness of clients to answer the questions for fear of being judged. Another theme that emerged was the centrality of the concept of one's relationship with God or Heavenly Father in LDS culture. In keeping with this value, respondents recommended phrasing questions in a way to explore this relationship. Thus, a related theme was the importance of exploring times of both closeness and distance in clients' relationship with God. Finally, a number of respondents indicated that the concept of "spiritual intimacy" was inconsistent with LDS culture and recommended asking about one's connection or closeness to God or Heavenly Father.

Conscience-Four comparatively minor themes emerged regarding this question set. First, it was noted that repentance and forgiveness are generally linked concepts in LDS culture. Second, mentioning the term "sin" might help in normalizing this teaching for clients. Third, it was mentioned that some LDS clients may struggle with shame, guilt, and perfectionism; hence it is important to be sensitive to these issues during the assessment process. Finally, it was observed that the concept of values might not resonate with some LDS clients.

Intuition-Analysis yielded one prominent theme. The language used to express the underlying concept was widely thought to be inconsistent with LDS culture. As a result, respondents recommended expressing the underlying ideas using terms such as "promptings from the Holy Ghost," "personal revelation," and to a lesser extent, "spiritual insights," and “dreams.”

Respondents suggested many helpful questions in the processing of answering the above qualitative items. Table 4 represents an attempt to synthesize many of the recommendations. It is important to note that this question set represents one of many that could have been constructed. The questions used to explore clients' spiritual stories should be adapted to correspond to each individual client's reality. The question set presented in Table 4, however, may serve as a useful starting point in work with many LDS clients. 


\section{Table 4. Alternative Spiritual History Question Sets for LDS Clients}

\section{Narrative Question Set}

Was your family part of a religious group? What religious practices did your family do together? How involved was your family? How did you feel about your level of involvement?

What sort of religious experiences (family home evenings, baptisms, blessings, temple, missions) stand out to you during your childhood and teenage years? How have these religious experiences influenced your later life? Did you embrace them as your own? Why or why not?

Do your current religious beliefs and practices differ from those in which you were raised? If so, how have they changed? Was there a time when your religious beliefs helped you through a particularly difficult time in life? At present, what religious beliefs are most important to you?

\section{Anthropological Question Set}

\section{- Personality}

Affect: What aspects of your religious life give you joy? What role does your faith play in handling adversity? Coping with life's challenges (fears)? Are there aspects of church involvement that are difficult for you? Or cause you guilt? How do you feel about your church leaders? How does your religion give you hope for the future? What religious goals do you hope to accomplish in the future?

Behavior: Are there particular religious practices, which you would be comfortable sharing with me, that help you deal with challenges (e.g., prayer, temple attendance, scripture reading, family home evening, or other religious practices or ordinances)? How active are you in your ward or branch? How does this compare to your past level of involvement? Are there individuals in your ward or branch (e.g., bishop, home or visiting teacher, relief society president) that are especially supportive? In what ways are they supportive?

Cognition: What religious beliefs are most important to you? What beliefs do you find particularly meaningful? What does your religion teach about personal trials? Does this belief help you overcome problems and difficulties? If so, how?

- $\quad$ Spirit

Communion: Describe your relationship with God or Heavenly Father. What has been your experience with Heavenly Father? How have these experiences influenced you? When have you felt especially close (distant) to Heavenly Father? Describe the last time you felt angry with or disappointed by Heavenly Father. How does your relationship with Heavenly Father help you face challenges? How would you describe your Father in Heaven? (His characteristics?) How would Heavenly Father describe you? (your strengths? limitations? personality?)

Conscience: How do you determine right and wrong? Can you describe a time when you followed (did not follow) what you felt was right? To what extent are your behaviors consistent with your religious beliefs? Do you ever struggle to know the difference between right and wrong? How did you resolve the confusion? How do you feel when you have done something wrong or sinful? What have you learned from such experiences? How does your religion help you deal with guilt? (shame? sin?) To what extent has the Church (your relationship with Heavenly Father) helped (hindered) your ability to forgive yourself (others?)

Intuition: To what extent have you had experiences where you felt Heavenly Father revealed things to you? Are there times when you are more (less) sensitive to receiving personal revelation? How do you distinguish between your own thoughts and the promptings from the Holy Ghost? To what degree have these spiritual insights influenced your life (the lives of others?) Have these insights been a strength in your life? If so, how? 


\section{Discussion}

LDS clients report the administration of a spiritual assessment is among the most effective interventions practitioners can employ in clinical settings (Martinez, Smith, \& Barlow, 2007). Yet few, if any, assessment methods have been validated for use with this population. The present study addressed this gap in the literature by modifying an existing spiritual history assessment tool for use with LDS clients.

The results suggest that spiritual histories represent a highly appropriate assessment method for LDS clients. At the conceptual level, respondents reported that this approach is congruent with LDS culture. The notion of telling one's spiritual story or religious testimony was perceived to be one that would resonate with most clients from this tradition.

Concurrently, considerable apprehension also emerged in this study. As noted in the introduction, the LDS population is very sensitive to biases regarding their beliefs and values in the broader society (Pew Research Center, 2012). Similar views were expressed in the present study. Respondents emphasized the importance of using culturally relevant language, the sensitive nature of LDS spirituality, and client concern about being misunderstood or disparaged by practitioners unfamiliar with the culture.

The findings underscore the importance of developing cultural competency prior to engaging clients (Haynes, 2001). Effective service provision is contingent upon developing a certain level of cultural competence with clients' spiritual beliefs and values (NASW Standards for Cultural Competence in Social Work Practice, 2001). This is particularly important in light of the repeated finding that most practitioners report receiving minimal training on spirituality and religion during their graduate educations (Canda \& Furman, 2010; Sheridan, 2009), in tandem with the growing emphasis on addressing spirituality by accrediting organizations such as the Joint Commission (Hodge, 2006).

To enhance their level of competency, practitioners might obtain specific resources that have been written with this aim in mind (Haynes, 2001; Ulrich et al., 2000). Forming relationships with LDS clergy, known as bishops, can often be helpful. For example, such religious experts are well positioned to assist in the process of distinguishing between symptoms of psychopathology and authentic expressions of faith. Practitioners may also consider establishing relationships with other colleagues who have more experience working with LDS clients. Such individuals can provide valuable therapeutic insights as well as offer options for referral (Reamer, 2006).

When administering assessments with LDS clients, it is critical to develop an atmosphere of trust and respect (Canda \& Furman, 2010). Toward this end, it is helpful to approach the assessment process with an attitude characterized by openness, humility, and a desire to learn from clients. To create a proper context for the assessment, one might begin by acknowledging that religious beliefs and practices are often highly personal and sensitive, explain the purpose for administering the assessment, ask for permission to proceed, and request forgiveness in advance for asking any questions that might inadvertently be offensive (Hodge \& Limb, 2009). As one respondent suggested, 
one might conclude by asking "are there spiritual taboos you would like me to be sensitive to?” (e.g., discussion of specifics relating to temple attendance).

It is important to reiterate that the question sets featured in Table 4 represent a working, rather than a definitive, assessment framework. The questions should be adapted to reflect each individual client's beliefs and values. While common LDS beliefs and practices should be legitimized, language that resonates with the client's worldview should be incorporated into the therapeutic dialogue.

Caution is warranted when using items from the anthropological question set, which can elicit a considerable amount of information. It is important to ensure that the dialogue remains focused on exploring data that is therapeutically relevant. The goal of the assessment should always remain on enhancing the client's wellness. Limiting the scope of the assessment in this manner also helps to safeguard sensitive dimensions of LDS spirituality.

In some cases, it may seem as if clients' beliefs and practices may be contributing to the presenting problem. Social workers, however, must respect clients' autonomy, including their right to self-determination in religious matters (NASW Code of Ethics, 2008). As the NASW Standards for Cultural Competence in Social Work Practice (2001) stipulates, social workers do not have to agree with clients' values in order to provide effective, culturally relevant services. As alluded to above, practitioners should exercise discernment and focus upon those dimensions of clients' spirituality that ameliorate the presenting problem (Garner, 2012; Hill \& Pargament, 2003).

The results must be interpreted in light of the study's limitations. The use of a nonprobability sampling methodology precludes generalizing the results. Although the regional representation helps to safeguard against any extant geographic bias, using a different sample of experts may produce a different set of findings. The use of a hybrid purposive/snowball sampling strategy, however, is an appropriate choice in light of the difficulty of obtaining a random sample of individuals with specialized knowledge of LDS culture (Babbie, 2010).

\section{Conclusion}

Spirituality plays a central role in LDS culture (Loser et al., 2008). In therapeutic settings, addressing spiritual beliefs and practices can play an instrumental role in enhancing outcomes among this population (Martinez et al., 2007; Thomas et al., 2011). Yet, few spiritual assessment approaches have been validated for use with this group, despite the profession's commitment to culturally competent practice (NASW Standards for Cultural Competence in Social Work Practice, 2001).

To assist practitioners address spirituality in a culturally competent manner, this study validated one spiritual assessment tool—spiritual histories-for use with LDS clients. Given the growth in this culturally distinct population, this study fills a significant gap in the literature. By providing practitioners with a validated tool for conducting culturally relevant assessments with LDS clients, practitioners are better equipped to 
utilize a strengths perspective and fulfill their mission of providing ethical and effective services.

\section{References}

Anderson, S. V. (2008). Rhetorical footing in Latter-day Saints counseling. Journal of Religion \& Spirituality in Social Work, 27(2), 323-339.

Babbie, E. (2010). The practice of social research (12 ${ }^{\text {th }}$ ed.). Belmont, CA: Wadsworth.

Barrios, M., Villarroya, A., Borrego, A., \& Olle, C. (2011). Response rates and data quality in web and mail surveys administered to $\mathrm{PhD}$ holders. Social Science Computer Review, 29(2), 208-220.

Canda, E. R., \& Furman, L. D. (2010). Spiritual diversity in social work practice: The heart of helping ( $2^{\text {nd }}$ ed.). New York, NY: Oxford University Press.

Chen, C. H. (2011). Marketing religion online: The LDS Church's SEO efforts. Journal of Media and Religion, 10, 185-205.

Cnaan, R., Evans, V., \& Curtis, D. W. (2012). Called to serve: The prosocial behavior of active Latter-day Saints. Philadelphia, PA: University of Pennsylvania, School of Social Policy \& Practice.

Corbin, J., \& Strauss, A. (2008). Basics of qualitative research ( $3^{\text {rd }}$ ed.). Thousand Oaks, CA: Sage Publications.

Dye, J. F., Schatz, I. M., Rosenberg, B. A., \& Coleman. (2000). Constant comparison method: A kaleidoscope of data. The Qualitative Report [On-Line Serial], 4(1/2), [24 paragraphs].

Furness, S., \& Gilligan, P. (2010). Religion, belief and social work: Making a difference. Bristol, UK: Policy Press.

Garner, M. D. (2012). The Social Work Integral Model (SWIM): A tool for conceptualizing the place for religious/spiritual/nonspiritual worldviews in practice. Religion and Spirituality Clearinghouse, a publication of the Council on Social Work Education. e1-e11. Retrieved from: http://www.cswe.org/File.aspx?id=58387

Haynes, D. T. (2001). Mormonism. In M. Van Hook, B. Hugen, \& M. Aguilar (Eds.), Spirituality within religious traditions in social work practice (pp. 251-272). Pacific Grove, CA: Brooks/Cole.

Hill, P. C., \& Pargament, K. I. (2003). Advances in conceptualization and measurement of religion and spirituality: Implications of physical and mental health research. American Psychologist, 58(1), 64-74.

Heerwegh, D., Vanhove, T., Matthijs, K., \& Loosveldt, G. (2005). The effects of personalization on response rates and data quality in web surveys. International Journal of Social Research Methodology, 8(2), 85-99. 
Hodge, D. R. (2001). Spiritual assessment: A review of major qualitative methods and a new framework for assessing spirituality. Social Work, 46(3), 203-214.

Hodge, D. R. (2002). Working with Muslim youths: Understanding the values and beliefs of Islamic discourse. Children and Schools, 24(1), 6-20.

Hodge, D. R. (2003). Spiritual assessment: A handbook for helping professionals. Botsford, CT: NACSW.

Hodge, D. R. (2004). Working with Hindu clients in a spiritually sensitive manner. Social Work, 49(1), 27-38.

Hodge, D. R. (2006). A template for spiritual assessment: A review of the JCAHO requirements and guidelines for implementation. Social Work, 51(4), 317-326.

Hodge, D. R., \& Gillespie, D. F. (2007). Phrase completion scales: A better measurement approach than Likert scales? Journal of Social Service Research, 33(4), 1-12.

Hodge, D. R., \& Limb, G. E. (2009). Spiritual histories and Native Americans: A mixed method validation study. Journal of Social Service Research, 35(4), 285-296.

Hodge, D. R., Limb, G. E., \& Cross, T. L. (2009). Moving from colonization toward balance and harmony: A Native American perspective on wellness. Social Work, 54(3), 211-219.

Linder, E. W. (2011). Yearbook of American and Canadian Churches. Nashville, TN: Abingdon Press.

Loser, R. W., Klein, S. R., Hill, E. J., \& Dollahite, D. C. (2008). Religion and the daily lives of LDS families: An ecological perspective. Family and Consumer Science Research Journal, 37(1), 52-70.

Marks, L. (2004). Sacred practices in highly religious families: Christian, Jewish, Mormon, and Muslim perspectives. Family Process, 43(2), 217-231.

Martinez, J. S., Smith, T. B., \& Barlow, S. H. (2007). Spiritual interventions in psychotherapy: Evaluations by highly religious clients. Journal of Clinical Psychology, 63(10), 943-960.

Melton, J. G. (2009). The encyclopedia of American religions ( $8^{\text {th }}$ ed.). Detroit, MI: Gale Research.

NASW Code of Ethics. (2008). Retrieved from http://www.socialworkers.org/pubs/code/code.asp

NASW Standards for Cultural Competence in Social Work Practice. (2001). Retrieved from http://www.socialworkers.org/practice/standards/NASWCulturalStandards.pdf

Nee, W. (1968). The spiritual man (Vol. 1-3). New York, NY: Christian Fellowship Publishers.

Pargament, K. I. (2007). Spiritually integrated psychotherapy: Understanding and addressing the sacred. New York, NY: Guilford Press. 
Pew Research Center. (2012). Mormons in America: Certain in their beliefs, uncertain of their place in society. Washington, DC: Pew Research Center's Forum on Religion \& Public Life.

Reamer, F. G. (2006). Social work values and ethics ( $3^{\text {rd }}$ ed.). New York, NY: Columbia University Press.

Sheridan, M. (2009). Ethical issues in the use of spiritually based interventions in social work practice: What we are doing and why. Journal of Religion and Spirituality in Social Work, 28(1/2), 99-126.

Shin, E., Johnson, T. P., \& Rao, K. (2012). Survey mode effects on data quality: Comparison of web and mail modes in a US national panel survey. Social Science Computer Review, 30(2), 212-228.

Thomas, A., Cunningham, K., \& Donnell, A. J. (2011). Differential efficacy of standard inpatient treatment between Mormon and non-Mormon patients. Mental Health, Religion \& Culture, 14(9), 935-943.

Ulrich, W. L., Richards, P. S., \& Bergin, A. E. (2000). Psychotherapy with Latter-day Saints. In P. S. Richards \& A. E. Bergin (Eds.), Handbook of psychotherapy and religious diversity (pp. 185-209). Washington, DC: American Psychological Association.

Van Hook, M., Hugen, B., \& Aguilar, M. A. (Eds.). (2001). Spirituality within religious traditions in social work practice. Pacific Grove, CA: Brooks/Cole.

\section{Author note:}

Address correspondence to David R. Hodge, Ph.D., School of Social Work, Mail Code 3920, 411 N. Central, Suite 800, Phoenix, Arizona, 85004-0689. 